Proceedings

\title{
Harvest Flight Synapse of Apis mellifera on the Vegetative Architecture of Cacti in the Sonoran Desert, Mexico ${ }^{+}$
}

\author{
Héctor Tecumshé Mojica-Zárate ${ }^{1, *}$, Luis Miguel Campos-Cardoso ${ }^{2}$ \\ 1 Universidad de la Sierra, Moctezuma, Sonora, México, C.P 84560; hectortecumshe@gmail.com \\ 2 Universidad Central "Marta Abreu” de Las Villas, Santa Clara, Cuba. C.P. 50100; lmcampos@uclv.edu.cu \\ * Correspondence: hectortecumshe@gmail.com; Tel.: 0053 (634) 3453622 \\ + Presented at the 1st International Electronic Conference on Entomology (IECE 2021), 1-15 July 2021; \\ Available online: https://iece.sciforum.net/.
}

Citation: Mojica-Zárate, H.; Campos-Cardoso, L.; Harvest Flight Synapse of Apis mellifera on the vegetative architecture of cacti in the Sonora desert, México, in Proceedings of the 1st International Electronic Conference on Entomology, 1-15 July 2021, MDPI: Basel, Switzerland, doi:10.3390/IECE-10533

Published: 1 July 2021

Publisher's Note: MDPI stays neutral with regard to jurisdictional claims in published maps and institutional affiliations.

Copyright: (c) 2021 by the authors. Submitted for possible open access publication under the terms and conditions of the Creative Commons Attribution (CC BY) license (http://creativecommons.org/licenses/by/4.0/).

\begin{abstract}
Harvest Flight Synapse (HFS)" refers to the way in which a pollinator communicates and interconnects the organization of a flower system through a sequence of flight performed through the space of the vegetative architecture of a plant. It was identified HFS of Apis mellifera performed in a territory of the desert of Sonora, Mexico by visual monitoring of Stenocereus thurberi cacti individuals, located around the periphery of a cultivation area of Medicago sativa during flowering's season. The importance of the HFS is that the pollinators establish a pre-designed flight transit order on the vegetative architecture so that subsequent visitors perform a flight sequence in which they include more floral structures, ensure pollination - harvest and at the same time stimulate the flowering. HFS prevailed initially from the east and the differences in time of stay in each column were not governed by their height or distance between them but by the number of columns with the presence of floral appendixes determined by their respective floral range and flowering scale. Communication and interconnection coexist in the bee-cactus relationship and allow sequencing the ecological processes in both organisms from the HFS.
\end{abstract}

Keywords: flight sequence; pollinating function; permanence in floral appendixes; vegetative architecture of cacti

\section{Introduction}

Pollinators present a severe challenge in the face of deforestation and the limited availability of flowering plants to make their environmental functions and survival [1-3]. This situation is no different for pollinating hymenopterans in geographic areas where their harvesting resources are limited for some cacti, the climatic emergency, atypical droughts and desert conditions [4-11].

The environmental service offered by honeybees (Apis mellifera) in the Sonoran desert represents an opportunity for the cacti that inhabit it to successfully maintain their species $[7,9,12,13]$. The pitaya cactus, Stenocereus thurberi, determines part of its life cycle with flowering with an increase in the months of April and June, thus completing the annual fructification from the fertilization provided by the bee at the time it makes its harvest flight $[6,8,14]$.

The understanding of this continuous process is not limited to a fortuitous path for the bee to perform such a valuable environmental service, it represents an interconnection and communication produced by the Apis mellifera harvest flight sequence in Stenecereus thurberi in which non-tangible latent values are integrated [15-21].

The purpose of this work is to establish the concept of Harvest Flight Synapse (HFS), which makes prevail possible latent and indirectly tangible aspects to understand that the harvest flight is not only determined by the stimulus that favors the presence of floral structures or by a random flight sequence but in order to establish an interconnection and 
possible communication among each column of the plant and its respective floral structures from the sequential and orderly visit of the bees to ensure a flowering in time $[1,8,19,22]$. These two aspects could be fundamental to design and formulate, for this cactacea, a synaptic flight map and the schematization of a sequence model from the observation of the flight sequence of a bee in the space of the vegetative architecture of Stenocereus thurberi [22-26].

This flight of the visiting bee, in the space of vegetative architecture, represents more than a visible environmental service of harvesting and pollination, it establishes a link between the plants that the bees visit to stimulate their development and ensure their reciprocal survival through a tacit communication between both organisms $[7,12,27]$. This meaning explains a cognitive - neuroanatomical association where predictability as well as information storage coexist, one more operation within the bee functions $[16,19,22,24,28-30]$.

\section{Materials and Methods}

\subsection{Study region and site}

The study was managed in the province of Moctezuma, Sonora, México, 658 above sea level $\left(29^{\circ} 42^{\prime} 01^{\prime \prime} \mathrm{N} ; 109^{\circ} 39^{\prime} 05^{\prime \prime} \mathrm{W}\right)$. The study area corresponds to a landscape of the Sonoran desert located in an intermontane valley in which an area of alfalfa meadow, Medicago sativa, is embedded; surrounded by legume trees and xerophytic vegetation.

A buffer area is distinguishable between the alfalfa meadow and the perimeter of native vegetation that ranges between 10 and 20 meters away. From there and up to 600 meters inland, the individuals of pitaya cactus, Stenocereus thurberi; were located and sampled. The sampling and observations were conducted on different dates from March 15 to June 6, 2021; between 6:00 am and 14:00 pm, the weather conditions during the sampling period were with an interval of temperature between $23^{\circ} \mathrm{C}$ to $43^{\circ} \mathrm{C}$, and none rainfalls during period and a wind speed oscillating it was about 24 to $32 \mathrm{~km} / \mathrm{h}$

\subsection{Graphic reference and vegetative plant architecture}

Each of one of the pitayas was geographically referenced, the time of observation and the environmental temperature were determined. A photograph was taken for each individual and the position per quadrant of its columns in a Cartesian plane was identified with respect to its individual center from its observation from the geographic south and from an aerial perspective. (Figure 1) [24, 29, 31].

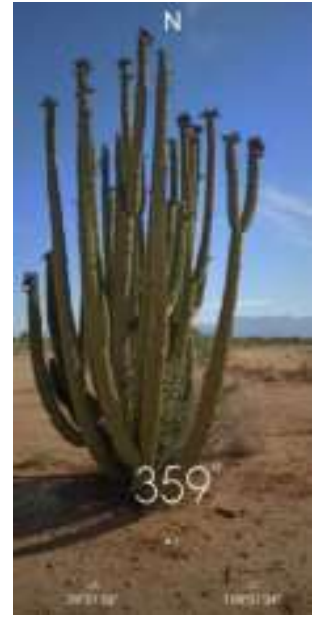

(a)

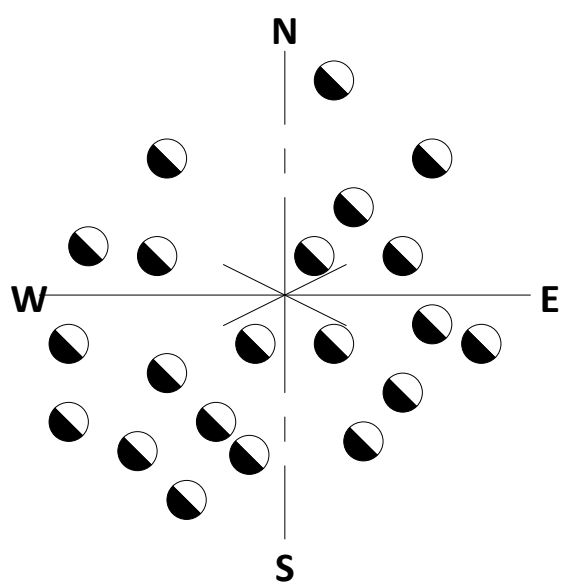

(b)

Figure 1. The vegetative architecture by the pitaya cactus in a Cartesian plane. a) With a perspective from the south, shows a specimen. b) This, same is visualized for the identification of the honeybee HFS from an aerial view 
The vegetative architecture of the plant consisted of identifying the height and amplitude of plant coverage, average height of the columns, average distance between columns, distance from the individual center, as well as the floral range and flowering scale of the floral appendages present in the coronary hood (Figure 2).

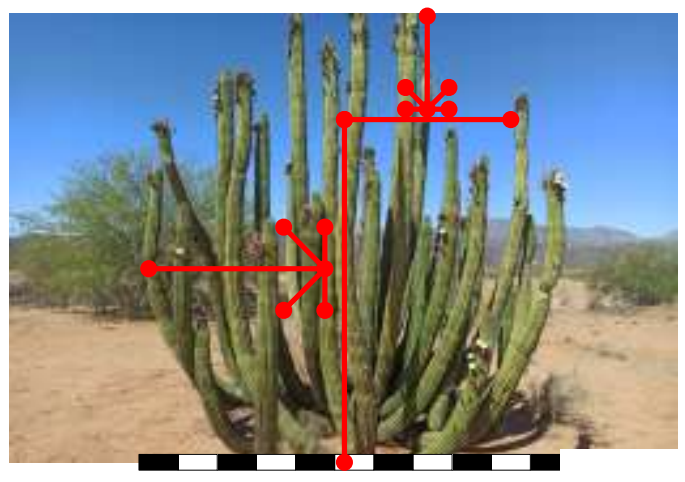

(a)

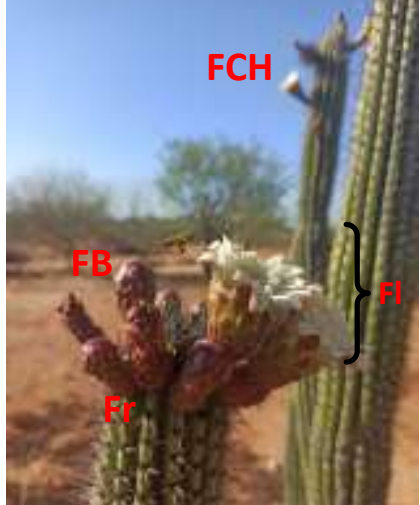

(b)

Figure 2. Vegetative architecture manifests in pitaya measurements, a) The total amplitude of the organism and perimeter limit, the distance between columns, the height, and the distance with reference to the center of the individual. $b$ ) The floral coronary hood $(\mathrm{FCH})$, with flower bulb $(\mathrm{FB})$, flower $(\mathrm{Fl})$, and fruit $(\mathrm{Fr})$

\subsection{Observation of flight behavior}

The observation to identify the Harvest Flight Synapse (HFS) consisted of the visual monitoring of the flight sequence together with the recording of the time spent by a single bee, Apis mellifera, visitor at a time on the vegetative architecture per individual of pitaya. The flight sequence was observed in the vegetative architecture of $n=21$ individuals of pitaya cactus in which the flight path of three and up to five bees was analyzed, obtaining an average of time per plant, for the total of events measured per date.

The time was measured in seconds from when the bee arrived in the airspace of the cactus until the moment where it left the plant. This measurement included the time in the sequence performed on each pitaya for each floral range and component of the plant's airspace.

\subsection{Descriptive analysis and interpretation of Harvest Flight Synapse model.}

The magnitudes for each of the variables involved in the HFS were processed and analyzed by descriptive analysis, dispersion measures were obtained and inferential tests were performed. The interpretation of a flight sequence model and the synaptic map of HFS is shown $[15,20,32]$. A hypothesis test is added to evaluate the time spent per visit in floral ranges $(\mathrm{P}<0.05)$. The software used was SPSS, version 25.

\section{Results}

\subsection{Vegetative architecture of Stenocereus thurberi}

The amplitude of cover and height of pitaya manifest the limits for understanding the vegetative architecture and airspace of the HFS. Height values ranged from a maximum of 5.4 meters to no less than 1.8; and amplitude of cover ranged from 0.8 to 2.4 meters (Figure 3). The average number of columns was 16 per pitaya, with maximum and minimum values of 38 and 3, respectively. From these magnitudes, the bees arrived in the airspace from the East $64 \%$ and from the Northeast $36 \%$ at an average pitaya height of 2.40 meters and then ascended to the crown cap of the highest pitaya column. On the way 
down, the bees had already visited $80 \%$ of the columns regardless of the existing floral range in these columns.

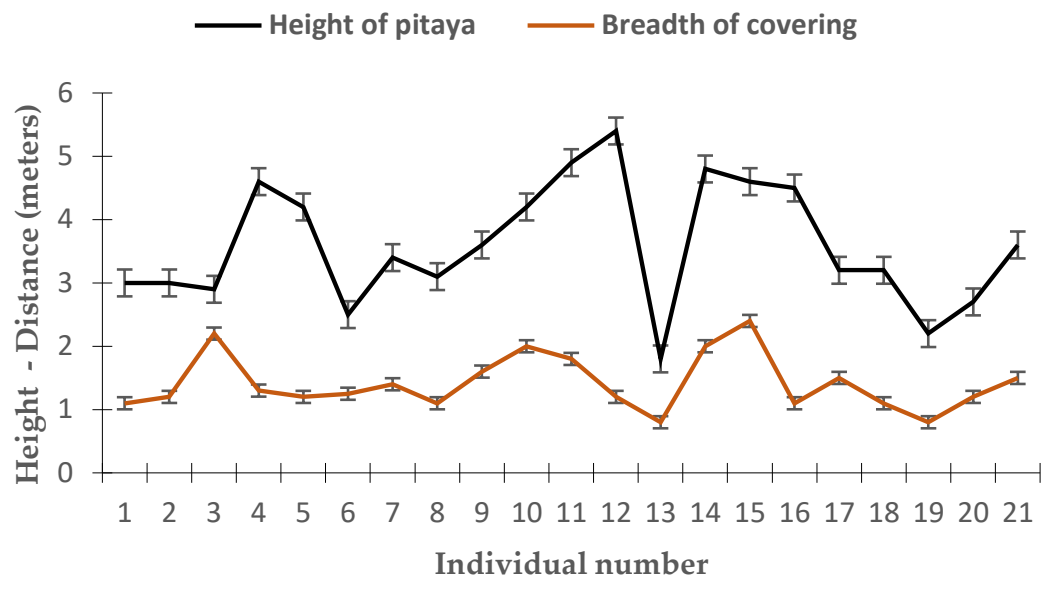

Figure 3. Vegetative architecture manifests in pitaya measurements, the total amplitude and height.

\subsection{Synaptic condition for flower structures}

Other elements that conditioned the HFS were, Average Column Height (ACH), Average Distance between Columns (ADC) and Average Distance between Columns and the Individual Center (ADCIC) (maximums and minimums respectively: 3.9 - 1.4; 1.1 - 0.35 and $1.8-0.25$ meters). The extreme values in column height defined part of the flight sequence in the direction of initial boarding to the airspace of the cactus. The intercolumnar separation determines part of the synaptic track that is formed among the columns; hence, a higher frequency of flights is identified in pitayas with columns with flower bulbs (Figure 4).

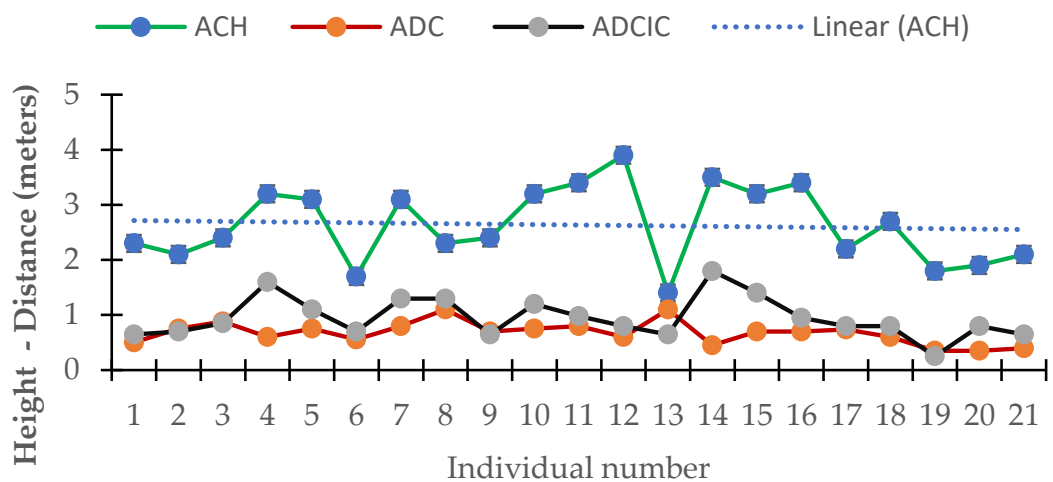

Figure 4. Intrinsic vegetative architecture consisting of Average Column Height $(\mathrm{ACH})$, Average Distance between Columns (ADC) and Average Distance between Columns and the Individual Center (ADCIC).

\subsubsection{Flower range and percentages}

Regarding the range and scale of the floral appendages present in the crown cap according to the total number of plants observed, most of them corresponded to flower bulbs. The percentages of floral range found in the total number of pitayas observed are represented according to Figure 5. 


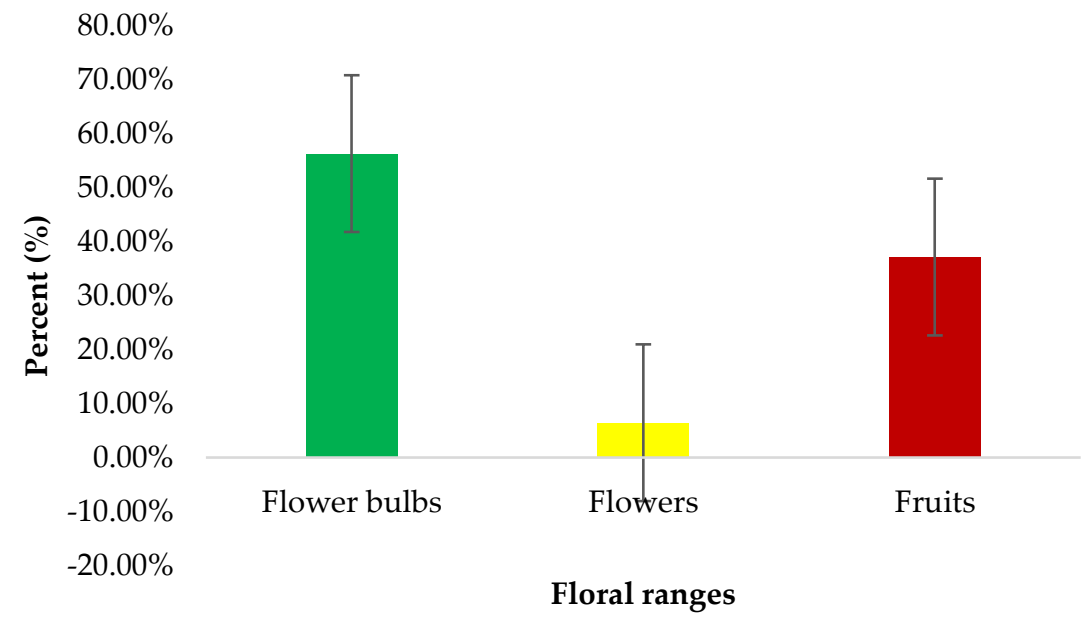

Figure 5. Percentage of floral appendixes present by the total of observed columns observed.

The visit sequence was defined in priority to columns with blooms. and flower bulbs, not ruling out those with growing fruits from the moment of arrival until the end of the visit to the cacti visited. The residence time in columns with floral appendixes was $47 \pm$ $3.2 \mathrm{~s}$; between columns with bulbs and fruits in formation for $5.2 \pm 1.6 \mathrm{~s}$

The time spent by the bee in each of the flight points or stay in the floral appendages as well as the recurrent actions performed on the pitaya are defined in the following HFS Sequence Model scheme (Table 1).

Table 1. HFS Sequence Model. Shows the floral range with residence time and priority action developed in the HFS sequence

\begin{tabular}{|c|c|c|}
\hline Stay point & Time $(\%)$ & Priority action developed \\
\hline $\begin{array}{c}\text { Vegetative architecture limit } \\
\text { of pitaya }\end{array}$ & 1.45 & Enter pitaya airspace \\
\hline \multicolumn{3}{|l|}{ Flower range } \\
\hline Floral bulb & 9.88 & $\begin{array}{l}\text { Close flight of flower stimu- } \\
\text { lation }\end{array}$ \\
\hline Flower & 72.96 & Harvest and pollination ${ }^{1}$ \\
\hline Fruit & 9.88 & $\begin{array}{c}\text { close flight to stimulate ma- } \\
\text { turity }{ }^{2}\end{array}$ \\
\hline Intercolumn airspace & 4.37 & Intercolumn flights \\
\hline $\begin{array}{c}\text { Vegetative architecture limit } \\
\text { of pitaya }\end{array}$ & 1.45 & $\begin{array}{l}\text { Exit pitaya airspace and } \\
\text { departure flight }\end{array}$ \\
\hline
\end{tabular}

${ }^{1}$ Primarily in flowers with a floral scale of $100 \%$

${ }^{2}$ Only in early stages of maturity

\subsubsection{Hypothesis test between floral structures and flight time.}

A difference was identified between the time the bee spent visiting flower bulbs and the time spent visiting flowers $(\mathrm{P}<0.05)$. In the case of fruits, there was no significant difference.Table S2

\subsection{Harvest Flight Synaptic Map}

The flight sequence in the harvesting flight synapse is represented by describing a Harvesting Flight Synaptic Map. The synapse is modeled with its elements. The original flight is highlighted in the foreground and the "flight track" formed by previous visiting 
bees in the background. Entry and exit are modeled as a possibility of arrival and when the bee leaves the pitaya's airspace (Figure 6).

This scheme denotes a sequence toward columns with coronary hoods with a diversity in number of floral ranges and scales. The model expresses the original flight path (OF) for the development of the harvest service as well as a relationship with the columns with flower bulbs. A sequence is evident in the model that involves columns with hoods with only flower bulbs or no open flowers. This suggests a subsequent "preparation" of the flower bulbs for subsequent tours and a tacit bee-flower bulb communication for the next flight sequence to be performed by another visitor.

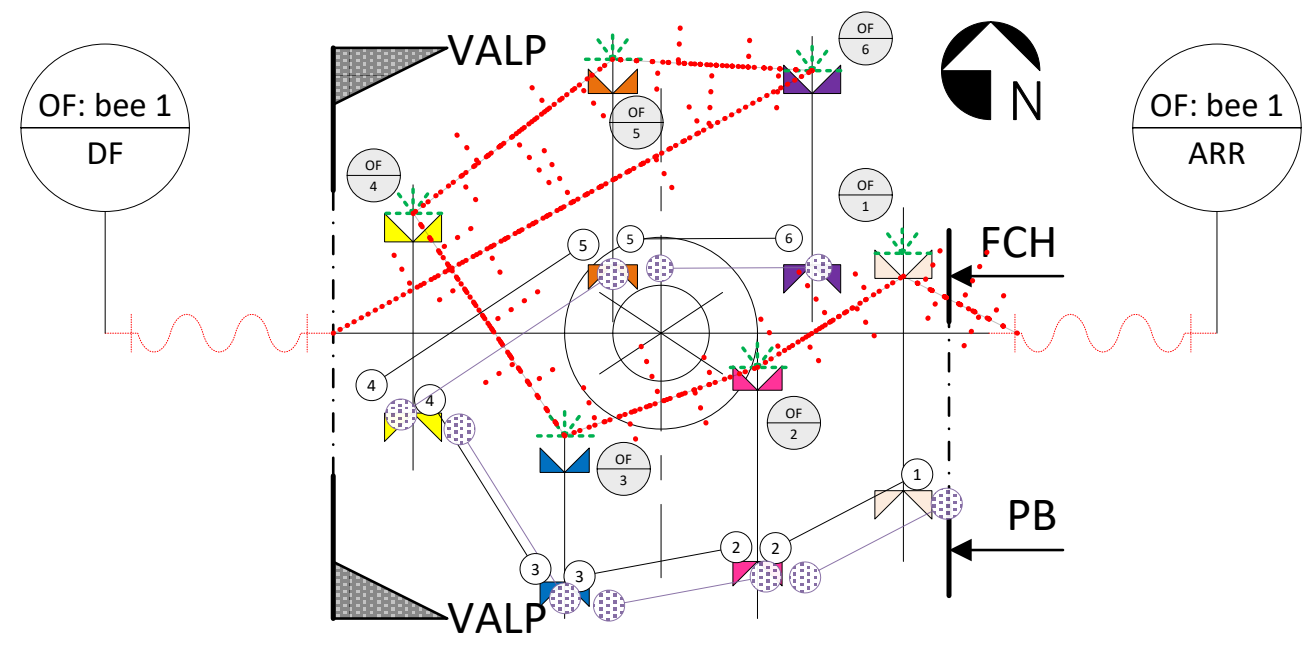

Figure 6. Synaptic Harvest Flight Map representing pitaya in the Cartesian plane with 6 theoretical internal contacts by the visiting bee in an equal number of columns. Vegetative architecture limit of pitaya (LVAP) represents the aerial space where the HFS elements are identified. In different colors the pitayas are observed, interconnected by the original flight (OF) (red dots) sequenced from the Arrival (ARR) to the take-off flight (DF), going to the different floral structures in the floral crown hood $(\mathrm{FCH})$ with the possibility of varying in sequence (lateral dots to the original route). At the base of the pitaya (PB), a synapse is articulated in the background that identifies a "flight track" elaborated by previous visitors and the relationship of the bees with the pitaya to stimulate subsequent flowering of flower bulbs or fruit ripening.

\section{Discussion}

\subsection{The flight sequence and vegetative architecture of Stenocereus thurberi}

In visiting bees, the HFS is important because it defines a pre-established flight sequence over the architecture of Stenocereus thurberi by the previous visiting bees and for subsequent visiting bees to perform a better designed flight sequence [17 - 19, 21, 22, 30]. With this prearranged flight sequence, columns with more bulbs or those bulbs close to flowering are integrated and an interfloral connection is established which may be due to the flight synapse $[8,28,30]$. This also suggests that HFS acts as a stimulus for bulb opening in the coronary hoods of plant columns where flowering moments are alternate in time $[23,33]$.

Regarding the flower range, an underestimation of the flower bulb count is possible. These bulbs fall due to natural conditions of the plant but the coronary hood generates sufficient flower bulbs that maintain the flight sequence [33,34]. A similar case occurred with immature fruits. The presence of mature fruits injured by other insects or by birds modified the time in the flight sequence per bee with stays of $7 \pm 1.18$ minutes.

In flowers, as the main visiting floral structure, the flight sequence was evident in flowers with a flower opening scale of 100\%. The HFS included flowers with flower opening scales between 5 - 25\% in which the bee made a connecting flight "circling" the structure but without stopping. 


\subsection{Interconnection and communication from HFS}

The synaptic map expresses an intrinsic, non-tangible relationship that interconnects the plant with each bee through a tangible stimulus [28]. This stimulus occurs when the bee travels through the growing floral structures, thus configuring an initial synapse [25]. Some authors mention Brownian or diffuse movements that seem to coincide with the movements observed in this study, but we consider that there is more than a Lévy movement, it is an intangible relationship that promotes this synaptic pathway in the cactus $[30,32,33,35-50]$. It is from this synapse that it is possible to explain the cognition of the pathway but at the same time it could partly explain latent stimuli related to the increase in flowering, development of floral structures, pollen production or fruit ripening $[17,18$, $22,24,34]$.

\section{Conclusions}

The Apis mellifera Harvest Flight Synapse, as a behavior and as an essential element in the ecological function, is determinant to maintain a level of resilience, order and vital maintenance of Stenocereus thurberi. HFS maintains the ecological harmony, the reduction of risks and the level of vulnerability in the ecosystem of the Sonoran desert produced by the climatic emergency and the existence of other and varied severe conditions.

The importance of the HFS is that the pollinators establish a pre-designed flight transit order on the vegetative architecture so that subsequent visitors perform a flight sequence in which they include more floral structures, ensure pollination - harvest and at the same time stimulate the flowering.

The flowering of Stenocereus, being annual and prevalent in spring, ensures its fruiting through sequenced visits by bees. In this ordered sequencing, a connection between floral structures at different stages of development alternately predominates [14]. The bee reproduces an organized sequence of visits between each of the columns that make up the plant to produce flowering in sequence.

The flower bulbs that are visited tangentially, while the adjacent flowers are visited for harvesting, stimulate their growth and development while generating a series of interconnections that suggest a "communication" and a link defined by the harvesting flight performed in an orderly sequence. This communication and interconnection coexist in the bee-cactus relationship and allow sequencing the ecological processes in both organisms from the HFS.

Supplementary Materials: The following are available online at www.mdpi.com/xxx/s1, Table S1: Variables for determination of Harvest Flight Synapse, Table S2: Hypothesis testing for time and flower ranges in Harvest Flight Synapse

Author Contributions: Conceptualization, H.M. and L.C.; methodology, H.M.; software, H.M.; validation, H.M., L.C.; formal analysis, H.M.; investigation, H.M.; resources, H.M.; data curation, H.M.; writing - original draft preparation, H.M. and L.C.; writing-review and editing, H.M. and L.C.; visualization, H.M. and L.C.; supervision, H.M. and L.C.; project administration, H.M. All authors have read and agreed to the published version of the manuscript.

Funding: This research received no external funding.

Institutional Review Board Statement: Not applicable.

Informed Consent Statement: Not applicable.

Data Availability Statement: The Data presented in this research work are available on request with the authors of this study

Acknowledgments: We would like to express our gratitude to María del Rayo Flores for let us to explore and to conduct, in Stenocereus thurberi, quantitative measures along - side on all periphery of her cultivation field area.

Conflicts of Interest: The authors declare no conflict of interest. 


\section{References}

1. Steffan-Dewenter, I., \& Kuhn, A. Honeybee foraging in differentially structured landscapes. Proceedings of the Royal Society B: Biological Sciences. 2003, 270(1515), 569-575.doi:10.1098/rspb.2002.2292

2. Willmer, P. G., \& Stone, G. N. Behavioral, Ecological, and Physiological Determinants of the Activity Patterns of Bees. Advances in the Study of Behavior. 2004, 347-466. doi:10.1016/s0065-3454(04)34009-x

3. Woodcock, B. A., Edwards, M., Redhead, J., Meek, W. R., Nuttall, P., Falk, S., Pywell, R. F. Crop flower visitation by honeybees, bumblebees and solitary bees: Behavioural differences and diversity responses to landscape. Agriculture, Ecosystems \& Environment. 2013. 171, 1-8. doi:10.1016/j.agee.2013.03.005

4. Erenler, H. E., Gillman, M. P., \& Ollerton, J. Impact of Extreme Events on Pollinator Assemblages. Current Opinion in Insect Science. 2020, 38: 34-39 doi:10.1016/j.cois.2020.01.007

5. Gotlieb, A., Hollender, Y., \& Mandelik, Y. Gardening in the desert changes bee communities and pollination network characteristics. Basic and Applied Ecology, 2011, 12(4), 310-320. doi:10.1016/j.baae.2010.12.003

6. Hung, K-LJ.; Kingston, J.; Albrecht, M.; Holway, D.; Kohn, J. The worldwide importance of honey bees as pollinators in natural habitats. Proc. R. Soc. 2018, B 285: 20172140. http://dx.doi.org/10.1098/rspb.2017.2140

7. Hall, D. M., \& Martins, D. J. Human dimensions of insect pollinator conservation. Current Opinion in Insect Science.2020, doi:10.1016/j.cois.2020.04.001

8. Ogilvie, J. E., \& Forrest, J. R. Interactions between bee foraging and floral resource phenology shape bee populations and communities. Current Opinion in Insect Science. 2017, 21, 75-82. doi:10.1016/j.cois.2017.05.015

9. Rodríguez, S..S., Pérez-Giraldo, L.C., Vergara, P.M., Carvajal, M. A., Alaniz, A. J. Native bees in Mediterranean semi-arid agroecosystems: Unravelling the effects of biophysical habitat, floral resource, and honeybees Agriculture, Ecosystems \& Environment. 2021,Volume 307, 28107188 doi.org/10.1016/j.agee.2020.107188

10. Vance, J. T., \& Roberts, S. P. The effects of artificial wing wear on the flight capacity of the honey bee Apis mellifera. Journal of Insect Physiology. 2014, 65, 27-36. doi:10.1016/j.jinsphys.2014.04.003

11. Visscher, P. K., Crailsheim, K., \& Sherman, G. How do honey bees (Apis mellifera) fuel their water foraging flights? Journal of Insect Physiology, 1996 42(11-12), 1089-1094. doi:10.1016/s0022-1910(96)00058-3

12. Lundin, O., \& Raderschall, C. A. Landscape complexity benefits bumble bee visitation in faba bean (Vicia faba minor L.) but crop productivity is not pollinator-dependent. Agriculture, Ecosystems \& Environment. 2021, Volume 314.107417. https://doi.org/10.1016/j.agee.2021.107417

13. Raw, A. Foraging Behaviour of Wild Bees at Hot Pepper Flowers (Capsicum annuum) and its Possible Influence on Cross Pollination. Annals of Botany. 2000, 85(4), 487-492. doi:10.1006/anbo.1999.1090

14. Abrol, D. P. Foraging Behaviour of Bees as Influenced by Quality and Quantity of Rewards from Flowers. Journal of Asia-Pacific Entomology. 2006. 9(2), 145-148. doi:10.1016/s1226-8615(08)60285-x

15. Warren, W. H., Rothman, D. B., Schnapp, B. H., \& Ericson, J. D. Wormholes in virtual space: From cognitive maps to cognitive graphs. 2017, Cognition, 166, 152-163. doi:10.1016/j.cognition.2017.05.020

16. Chittka, L. Bee cognition. Current Biology. 2017, 27(19), R1049-R1053. doi:10.1016/j.cub.2017.08.008

17. Collett, T. S., \& Zeil, J. Insect learning flights and walks. Current Biology. 2018, 28(17), R984-R988.doi:10.1016/j.cub.2018.04.050

18. Collet, T.S., Graham, P. Insect Navigation: Do Honeybees Learn to Follow Highways? Current Biology. 2015, 25: 240-242. https://doi.org/10.1016/j.cub.2014.11.003

19. Degen, J., Kirbach, A., Reiter, L., Lehmann, K., Norton, P., Storms, M., Menzel, R. Exploratory behaviour of honeybees during orientation flights. Animal Behaviour 2015, 102, 45-57. doi:10.1016/j.anbehav.2014.12.030

20. Moeser, S. D. Cognitive mapping in a complex building. Environment and Behavior. 1988, 20, $21-49$.

21. Santana-Filho, J. V., Raposo, E. P., Macêdo, A. M. S., Vasconcelos, G. L., Viswanathan, G. M., Bartumeus, F., \& da Luz, M. G. E. (2020). A Langevin dynamics approach to the distribution of animal move lengths. Journal of Statistical Mechanics: Theory and Experiment. 2020, (2), 023406. doi:10.1088/1742-5468/ab6ddf

22. Giurfa, M. Honeybees foraging for numbers. Journal of Comparative Physiology A. 2019, 205:439-450 doi:10.1007/s00359-01901344-2

23. Bänsch, S., Tscharntke, T., Ratnieks, F., Härtel, S., \& Westphal, C. Foraging of honey bees in agricultural landscapes with changing patterns of flower resources. Agriculture, Ecosystems \& Environment. 2020, 291, 106792. doi:10.1016/j.agee.2019.106792

24. Cheeseman, J. F., Millar, C. D., Greggers, U., Lehmann, K., Pawley, M. D. M., Gallistel, C. R., Menzel, R. (2014). Way-finding in displaced clock-shifted bees proves bees use a cognitive map. Proceedings of the National Academy of Sciences. 2014, 111(24), 89498954. doi:10.1073/pnas.1408039111

25. Ikeno, H. Flight control of honeybee in the Y-maze. Neurocomputing. 2004, 58-60, 663-668.doi:10.1016/j.neucom.2004.01.111

26. Wang, H., Fu, Q., Wang, H., Baxter, P., Peng, J., Yue, S. A bioinspired angular velocity decoding neural network model for visually guided flights. Neural Networks. 2021, 136 180-193 https://doi.org/10.1016/j.neunet.2020.12.008

27. Hennessy, G., Harris, C., Eaton, C., Wright, P., Jackson, E., Goulson, D., \& Ratnieks, F. F. L. W. Gone with the wind: effects of wind on honey bee visit rate and foraging behaviour. Animal Behaviour. 2020. 161, 23-31. doi:10.1016/j.anbehav.2019.12.018

28. Baird, E., Tichit, P., \& Guiraud, M. The neuroecology of bee flight behaviours. Current Opinion in Insect Science. 2020, doi:10.1016/j.cois.2020.07.005 
29. Menzel, R., Greggers, U., Smith, A., Berger, S., Brandt, R., Brunke, S., \& Watzl, S. (). Honey bees navigate according to a maplike spatial memory. Proceedings of the National Academy of Sciences. 2005,102, 3040-3045 www.pnas.org/cgi/doi/10.1073/pnas.0408550102.

30. Riley, J. R., Greggers, U., Smith, A. D., Stach, S., Reynolds, D. R., Stollhoff, N., Menzel, R. The automatic pilot of honeybees. Proceedings of the Royal Society B: Biological Sciences. 2003, 270(1532), 2421-2424. doi:10.1098/rspb.2003.2542

31. Zhang, H.-T., Wang, N., Chen, M. Z. Q., Su, R.-Q., Zhou, T., \& Zhou, C. Spatially quantifying the leadership effectiveness in collective behavior. New Journal of Physics. 2010. 12(12), 123025. doi:10.1088/1367-2630/12/12/123025

32. Gould, J. L. The Locale Map of Honey Bees: Do Insects Have Cognitive Maps? Science. 1986. 232(4752), 861-863. doi:10.1126/science.232.4752.861

33. Humphries, N. E., Weimerskirch, H., Queiroz, N., Southall, E. J., \& Sims, D. W. Foraging success of biological Levy flights recorded in situ. Proceedings of the National Academy of Sciences. 2012, 109(19), 7169-7174.doi:10.1073/pnas.1121201109

34. Esposito, F.; Costa, R.; Boieiro, M. Foraging Behavior and Pollen Transport by Flower Visitors of the Madeira Island Endemic Echium candicans. Insects 2021, 12, 488. https://doi.org/10.3390/insects12060488

35. Bartumeus, F., \& Catalan, J. Optimal search behavior and classic foraging theory. Journal of Physics A: Mathematical and Theoretical. 2009. 42(43), 434002. doi:10.1088/1751-8113/42/43/434002

36. Cheung, A., Collett, M., Collett, T. S., Dewar, A., Dyer, F., Graham, P., Zeil, J.. Still no convincing evidence for cognitive map use by honeybees: Fig. 1. Proceedings of the National Academy of Sciences. 2014, 111(42), E4396-E4397. doi:10.1073/pnas.1413581111

37. Faustino, C. L., Silva, L. R. da, Luz, M. G. E. da, Raposo, E. P., \& Viswanathan, G. M. Search dynamics at the edge of extinction: Anomalous diffusion as a critical survival state. Europhysics Letters (EPL) 2007, 77(3), 30002. doi:10.1209/0295-5075/77/30002

38. Kawai, R. Continuous-time modeling of random searches: statistical properties and inference. Journal of Physics A: Mathematical and Theoretical. 2012, 45(23), 235004. doi:10.1088/1751-8113/45/23/235004

39. Menzel, R., Brandt, R., Gumbert, A., Komischke, B., \& Kunze, J. Two spatial memories for honeybee navigation. Proceedings of the Royal Society B: Biological Sciences. 2000, 267(1447), 961-968. doi:10.1098/rspb.2000.1097

40. Padash, A., Chechkin, A. V., Dybiec, B., Pavlyukevich, I., Shokri, B., Metzler, R. First-passage properties of asymmetric Lévy flights. Journal of Physics A: Mathematical and Theoretical. 2019, 52 (45), . https://doi.org/10.1088/1751-8121/ab493e

41. Palyulin, V., Blackburn, G., Lomholt, M. A., Watkins, N., Metzler, R., Klages, R., \& Chechkin, A. First passage and first hitting times of Lévy flights and Lévy walks. New Journal of Physics. 2019, doi:10.1088/1367-2630/ab41bb

42. Raposo E P., Buldyrev, S. V., da Luz, M.G., Viswanathan, G. M. \& Stanley, H. E. Lévy flights and random searches. J. Phys. A: Math. Theor. 2009, doi:10.1088/1751-8113/42/43/434003 L 42, 434003

43. Reynolds, A. M. Cooperative random Lévy flight searches and the flight patterns of honeybees. Physics Letters A. 2006. 354(56), 384-388. doi:10.1016/j.physleta.2006.01.086

44. Reynolds, A. M. Avoidance of conspecific odour trails results in scale-free movement patterns and the execution of an optimal searching strategy. Europhysics Letters (EPL). 2007, 79(3), 30006. doi:10.1209/0295-5075/79/30006

45. Reynolds, A. M. Optimal random Lévy-loop searching: New insights into the searching behaviours of central-place foragers. EPL (Europhysics Letters). 2008, 82(2), 20001. doi:10.1209/0295-5075/82/20001

46. Reynolds, A. M. Scale-free animal movement patterns: Lévy walks outperform fractional Brownian motions and fractional Lévy motions in random search scenarios. Journal of Physics A: Mathematical and Theoretical. 2009, 42(43), 434006. doi:10.1088/17518113/42/43/434006

47. Reynolds, A. M. Effective leadership in animal groups when no individual has pertinent information about resource locations: How interactions between leaders and followers can result in Lévy walk movement patterns. EPL (Europhysics Letters).2013, 102(1), 18001. doi:10.1209/0295-5075/102/18001

48. Vallaeys V, Tyson RC, Lane WD, Deleersnijder E, Hanert E. A Lévy flight diffusion model to predict transgenic pollen dispersal. J. R. Soc. Interface. 2017 14: 20160889. http://dx.doi.org/10.1098/rsif.2016.0889

49. Viswanathan, G.M., Raposo, E.P., da Luz, M.G. Lévy flights and superdiffusion in the context of biological encounters and random searches., Physics of Life Reviews. 2008 5, 3, 133-150

50. Yi, M., Yuen, R. K. K., \& Lee, E. W. M. Transition from positive to negative on the leadership effect of the biological particles group. EPL. Europhysics Letters. 2016, 114(1), 18003. doi:10.1209/0295-5075/114/18003 